\title{
Temporal and atemporal uses of 'you': indexical and generic second person pronouns in English, German, and Dutch
}

\author{
Bettina Gruber ${ }^{1}$
}

Received: 16 August 2015 / Accepted: 10 December 2016/ Published online: 22 September 2017 (C) The Author(s) 2017. This article is an open access publication

\begin{abstract}
Second person singular pronouns are widely used in generic contexts, referring to people in general rather than to the single addressee of the utterance. Based on the assumption that pronouns are morphosyntactically complex elements, this paper argues that only pro- $\phi$ Ps in the sense of Déchaine and Wiltschko (2002) are licit in those environments while fully fledged pro-DPs are necessarily interpreted indexically. It is argued that the latter contain an interpretable but unvalued TIME-feature in $\mathrm{D}$ which restricts the interpretation of the entire structure to a specific temporal stage of the individual denoted by the pronoun. The article shows that in German, English, and Dutch this TIME-feature is valued by utterance time, thus leading to an indexical interpretation of the pronoun. From a broader perspective, the TIME-feature is proposed to be universally present in indexical pronouns. Ultimately, its properties are responsible for crosslinguistic variation in the syntax and semantics of first and second person pronouns.
\end{abstract}

Keywords Pronouns · Indexicals · Generics · Temporal restriction · Second person

\section{Introduction}

Crosslinguistically, second person pronouns frequently appear in contexts in which they refer to people in general rather than to the actual addressee of the utterance (cf. Siewierska 2004:212; Gruber 2013:124), as in (1):

Bettina Gruber

b.gruber@uu.nl

1 Utrecht University, Trans 10, 3512 JK Utrecht, The Netherlands 
(1) In the '20s, you had to wear a hat.

In its most salient reading, this statement is not (just) about the addressee but more generally about people who lived in the '20s. The second person pronoun is thus interpreted generically rather than indexically. Based on data from English, German, and Dutch, this paper offers a novel perspective on how these readings come about: Couched in the view that pronouns are morphosyntactically complex elements, I propose that the different readings also involve structurally distinct second person pronouns. Following Bliss and Gruber (2015), I claim that indexical pronouns contain a temporal layer which functions as a restrictor on the interpretation of the whole structure. Further developing this idea, I propose that in German, English, and Dutch this temporal layer references the utterance time, thereby restricting the interpretation to the utterance context and forcing an indexical reading. Conversely, if this layer is absent then the pronoun's interpretation is not restricted and can thus refer either generically or indexically, depending on the context. This paper is structured as follows: in Sect. 2, I introduce the core data from English, German, and Dutch. Next, in Sect. 3 I introduce the analysis, detailing the specifics based on Dutch. This is followed by an extension of the analysis to English and German in Sect. 4. The penultimate Sect. 5 discusses how this analysis can be extended beyond generic and indexical readings. Lastly, I summarize and briefly discuss the crosslinguistic application of the analysis in Sect. 6.

\section{The data}

Just as illustrated in (1) for English, German can also use a second person pronoun to refer to people in general. This is shown in (2). ${ }^{1}$

(2) Im 19. Jahrhundert konntest du in Wien oft berühmte Künstler in in.the 19th century could you in Vienna often famous artists in den Kaffeehäusern antreffen.

the cafés meet

'In the 19th century, you could often meet famous artists in cafés in Vienna.'

As a next step we want to see whether there are any restrictions on when a second person pronoun can be used to refer to people in general. The single most important restriction becomes evident in the examples in (3) and (4) and their respective formalizations:

(3) Wenn du allergisch auf Hunde bist, bist du nicht automatisch auch auf if you allergic on dogs are are you not automatically also on

Katzen allergisch.

cats allergic

'If you indexical $_{\text {are allergic to dogs, you }}$ indexical are not also necessarily allergic to cats.'

also: 'If one is allergic to dogs, one is not also necessarily allergic to cats.'

\footnotetext{
1 The core data of this research were collected in three ways: (i) a written questionnaire whose main goal was a broad cross-linguistic overview of non-indexical uses of second person pronouns, (ii) additional, more specific elicitations distributed via e-mail, and (iii) personal interviews with native speakers. The majority of the language consultants were linguists.
} 
Table 1 Dutch singular pronominal paradigm

\begin{tabular}{lllll}
\hline & $\begin{array}{l}\text { Subject } \\
\text { strong }\end{array}$ & Weak & $\begin{array}{l}\text { Object } \\
\text { strong }\end{array}$ & Weak \\
\hline First person & ik & 'k & mij & me \\
Second person & jij & je & jou & je \\
Third person feminine & zij & ze & haar & 'r \\
Third person masculine & hij & ie & hem & 'm \\
\hline
\end{tabular}

(4) Immer wenn ich in Holland bin, stiehlst du mir mein Rad. always when I in Holland am steal you me my bike

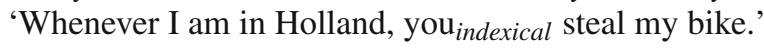

These examples illustrate the well-known fact that a second person pronoun can only be interpreted impersonally under generic quantification (3), and is necessarily interpreted indexically under existential quantification (4) (cf. Cinque 1988; Kitagawa and Lehrer 1990; Egerland 2003; Alonso-Ovalle 2002). Generic sentences are standardly analysed as involving a generic operator that quantifies over the relevant variables in its scope (Carlson 1989; Carlson and Pelletier 1995; Krifka et al. 1995; Chierchia 1995); as I will argue later on, the second person pronoun is one of those variables. Naturally, this relates to the fact that in any case there is a principled opposition between an existential and a generic interpretation of noun phrases, as widely discussed in the literature (cf. among many others Carlson 1980; Krifka et al. 1995; Kratzer 1995; Cohen and Erteschik-Shir 2002). This again ties in with the principled distinction between episodic and generic sentences: episodic statements report single events whereas generic sentences report multiple events. I will return to this distinction in Sect. 4.3.

Another interesting restriction becomes obvious once we include languages that, unlike Standard German or Standard English, have more than just one pronoun to refer to the addressee of an utterance: A typical case of such a language is Dutch. It has two sets of personal pronouns, corresponding to weak and strong forms, as summarized for the singular in Table 1 (Koster 1978; Berendsen 1986; Everaert 1986; Zwart 1996). The paradigm shows that the weak and strong forms are all phonologically related with the former being reduced forms of the latter. ${ }^{2}$ For the remainder of the paper, I will refer to the phonologically lighter form 'je' as weak and to the second form 'jij' as strong.

The sentences in (5) illustrate both pronouns and their respective range of interpretation:

(5) a. In Nederland leerde je fietsen zelfs voordat je leerde lopen. in Netherlands learned you weak cycle even before you weak learned walk 'In the Netherlands, you indexical $_{\text {learned to ride a bike before you }}$ indexical $_{\text {even }}$ learned to walk.'

also: 'In the Netherlands, one learned to ride a bike before one even learned to walk.'

\footnotetext{
2 Berendsen (1986) proposes that while diachronically the two forms may well have surfaced due to mere phonological reduction, synchronically they are independent of each other.
} 
Table 2 Available readings of second person pronouns

\begin{tabular}{lll}
\hline & Indexical & Generic \\
\hline English 'you' & $\checkmark$ & $\checkmark$ \\
German 'du' & $\checkmark$ & $\checkmark$ \\
Dutch weak 'je' & $\checkmark$ & $\checkmark$ \\
Dutch strong 'jij' & $\checkmark$ & - \\
\hline
\end{tabular}

b. In Nederland leerde jij fietsen zelfs voordat jij leerde lopen.

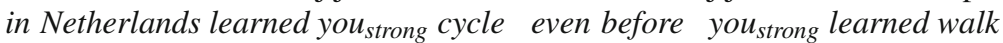
'In the Netherlands, you indexical $_{\text {learned to ride a bike before } \text { you }_{\text {indexical }} \text { even }}$ learned to walk.'

not: 'In the Netherlands, one learned to ride a bike before one even learned to walk.'

The sentence in (5a) with the weak pronoun ' $\mathrm{je}$ ' is ambiguous between an indexical and a generic interpretation. However, it is completely impossible to assign (5b) a generic meaning. ${ }^{3}$ The same pattern holds generally: the strong pronoun 'jij' will always be interpreted as referring to the addressee, whereas the weak pronoun 'je' can either refer indexically or generically. The core data that this paper seeks to analyse can thus be summarized as in Table 2 .

To sum up, I have shown that in addition to the restriction to generic contexts there is also a morphosyntactic restriction on the generic interpretation of second person pronouns: Dutch strong second person pronouns are necessarily interpreted indexically. Consequently, they are excluded from generic sentences, which refer to people in general. Only weak second person pronouns can appear in these contexts and take on generic meaning.

\section{The analysis}

A fundamental assumption for the present analysis is that pronouns are internally complex elements as for instance argued for by Postal (1966), Abney (1987), Cardinaletti and Starke (1999), Déchaine and Wiltschko (2002) and van Koppen (2005). The present analysis is specifically based on the proposal developed in Déchaine and Wiltschko (2002). They suggest that pronouns come in three different guises: pro-DP, pro- $\phi \mathrm{P}$, or pro-NP, as schematized in (6):

(6) a.

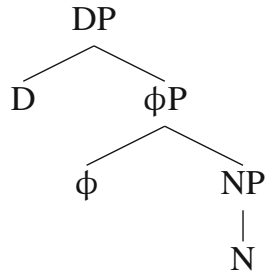

b.

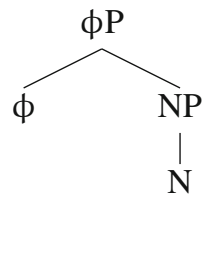

c. NP<smiles>[NH]</smiles>

\footnotetext{
${ }^{3}$ In fact, using two instances of 'jij' even seems slightly odd to some speakers as it invokes a strong focus. Using the weak pronoun 'je' instead of the second strong 'jij' in each sentence makes the examples sound more natural.
} 
In what follows, I extend their analysis and propose that the morphosyntactic content of indexical, i.e., first and second person, pronouns is more specific than suggested by the structure in (6). I start with the lower part of the structure before turning to the core topic of this paper, the D-layer, in the next section.

I propose that the nominal base of indexical pronouns is the silent noun MAN. ${ }^{4}$ It stands for an entity specified as [+ sentient]. ${ }^{5}$ Sentience refers to consciousness, or the ability to think, reflect, feel, or be "capable of internal experience" (Speas and Tenny 2003:328) and thus includes any individual that can be understood as acting consciously and holding a mental state, e.g., also cartoon characters or robots. ${ }^{6}$ Speas and Tenny (2003) explicitly describe first and second person as sentient: "[They] refer to the unique sentient individuals that are the participants in the discourse." (Ibid.:330)

This silent noun MAN is similar to Elbourne's (2005) silent noun ONE, which he defines as follows:

[L]et ONE be a phonologically null noun with interpretation

$\left[\lambda x: x \in D_{e} \cdot x \in D_{e}\right]$, which can appear in the argument slot for $\mathrm{a}[\mathrm{n}]$ $[\ldots]$ NP provided by a pronoun.

[Elbourne 2005:124]

In other words, Elbourne's (2005) ONE is a predicate over individuals and of type $<e, t>$. Correspondingly, I propose that the silent noun MAN that occupies the nominal component of an indexical pronoun has the interpretation in (7): ${ }^{7}$

(7) $\left[\lambda x: \operatorname{sentient}(x) \cdot x \in D_{e}\right]$

This function maps sentient individuals to the truth value 1 (true) whenever the input is a sentient individual, since only entities of type $e$ can be sentient; otherwise, the function is undefined. In that case the utterance containing the indexical pronoun cannot be interpreted due to presupposition failure, in the sense of Heim and Kratzer (1998, 81f.).

As in Déchaine and Wiltschko (2002), the $\phi P$-layer contains information about the person that the pronoun refers to. For the purposes of this paper, I assume that

\footnotetext{
4 MAN is a purely terminological choice and bears no connection to the Germanic impersonal 'man'.

5 Third person pronouns which can refer to sentient and non-sentient entities alike are assumed not to contain MAN. One analysis of third person pronouns compatible with the analysis of indexical pronouns developed here is that of Elbourne (2005): He analyses third person pronouns as hidden definite descriptions along with proper names and definite descriptions. However, the specifics of his proposal are left aside here, since I explicitly focus on second person pronouns.

6 While the feature appears to be reminiscent of Reinhart's (2002) feature $[+\mathrm{m}]$ (mental state holder), there is an important difference: Reinhart's feature is an attribute of theta-roles. For example, a patient will always be $[-\mathrm{m}]$ even if it is a sentient individual.

7 Recently Wiltschko and Ritter (2015) argued that a specific class of nouns referring to "human(oid)" entities contains a human restriction in Spec-DP. Specifically, whether or not the abstract argument located in Spec-DP is associated with humanness (in their analysis with an "H-index") "depends on the real world referent of the noun" (ibid.). Thus, it does not in and of itself restrict the possible range of referents of the noun denoted by the entire DP. In fact, in most cases the lexical content of the noun itself will contribute to whether or not the argument in Spec-DP bears an H-index: "Thus, if the noun denotes a human (e.g., 'girl'), then the [abstract argument] associated with the functional architecture above that noun will denote a human referent as well." Consequently, their analysis is readily compatible with the present proposal about second person pronouns: the silent nominal MAN is the pronominal equivalent to, e.g., 'girl'.
} 
this layer simply contains a second person feature [2P] which always picks out the addressee of an utterance. ${ }^{8}$ The specifics of the DP-layer form the core of this paper and are explained in detail below. I start by determining the structural status of Dutch second person pronouns, followed by an account of the contribution of D.

\subsection{The morphosyntactic status of Dutch second person pronouns}

I analyse the strong Dutch pronoun 'jij' as a full DP and the weak form 'je' as a $\phi P$, with the underlying structures given in (8).

(8)

a. Strong pronoun: 'jij'

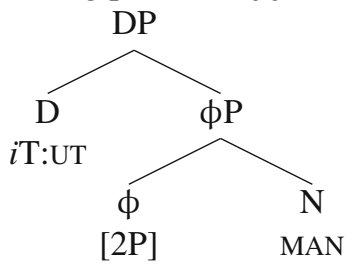

b. Weak pronoun: 'je'

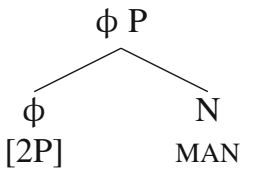

According to Déchaine and Wiltschko (2002), this implies that 'jij' is semantically definite whereas the status of 'je' in this respect is indeterminate. Recall that 'jij' has been shown to be necessarily indexical, i.e., clearly definite, whereas 'je' can either be indexical or generic, i.e., indeterminate. Further, following Déchaine and Wiltschko (2002), we expect only 'je' to be able to act as a variable and thus be bound. This is actually the case in the examples already discussed: following the standard analysis of generic sentences (Carlson 1989; Carlson and Pelletier 1995; Krifka et al. 1995; Chierchia 1995), I assume that they contain a generic operator GEN that binds the relevant variables in its scope. The generic reading of a simple example as in (9a) then corresponds to $(9 b)$.

(9) a. Je groet een buurman.

you weak greet a neighbour.

'One greets a neighbour.'

b. GEN $[\mathrm{x}, \mathrm{y}, \mathrm{s} ;]$ ( $\mathrm{x}=$ sentient individual; $\mathrm{y}=$ neighbour of $\mathrm{x} \& \mathrm{x}$ and $\mathrm{y}$ in $\mathrm{s} \&$ $\mathrm{x}$ greets $\mathrm{y}$ )

Essentially this says that whenever there is a situation which has both a sentient individual and a neighbour in it, this individual greets the neighbour. ${ }^{9}$ Syntactically, it is generally assumed that sentence level genericity implies that GEN is encoded in the

\footnotetext{
8 In Gruber (2013), this projection is analysed as an AtP rather than a $\phi P$ : There it is proposed that indexical pronouns actually consist of a spatial and a temporal component. While D contains the temporal part, as argued for here, the indexical equivalent to $\phi \mathrm{P}$ is argued to contain the spatial component. However, the details of that analysis go beyond the purposes of this paper.

9 The precise semantics of GEN are arguably more intricate than the representation in (9b) implies, since GEN does not universally quantify but allows for exceptions. Rather, as suggested by Heim (1982); Krifka et al. (1995) it is probably a modal operator that evokes a modal base with respect to which the statement is evaluated.
} 
left periphery of the clause (cf., e.g., Moltmann 2006) and thus takes scope over all the relevant variables it needs to bind. Since I am not attempting a semantic account of the interpretation of such sentences, I limit myself to the following claim here: a generic interpretation of an otherwise indexical pronoun is only possible if the indexical can be bound by a generic operator. Therefore, it needs to correspond to a pronominal structure that allows binding; according to the account by Déchaine and Wiltschko (2002), it therefore needs to be a pro- $\phi$ P. Conversely, this excludes pro-DPs from such structures as they cannot function as bound variables.

Consequently, this analysis includes the claim that a pro- $\phi \mathrm{P}$ can either be used generically or indexically. ${ }^{10}$ This option is already included in Wiltschko's (2002) proposal. For instance, they analyse French first and second person clitics as pro- $\phi$ Ps, based on the fact that they can be bound. ${ }^{11}$ As for the Dutch data, I propose that in both the indexical and the generic uses of a $\phi \mathrm{P}$ pronoun ' je', the pronoun itself always picks out the addressee of the utterance. However, in generic contexts, i.e., by virtue of being bound by a generic operator GEN, its interpretation gets expanded from the addressee to people in general. ${ }^{12}$

At this point, some further data need to be discussed which at first seem to constitute an exception to the generalization that strong pronouns are necessarily indexical. While the majority of speakers' judgements elicited for the present study were consistent and clear throughout, Tarenskeen (2010) and de Hoop and Tarenskeen (2014) report instances of strong pronouns in what they analyse as generic contexts. However, further elicitation (cf. Gruber 2013) refines the picture and brings to light a restriction that seems to apply in cases of non-indexical uses of the strong pronoun 'jij': While not everyone accepts the strong pronoun in generic contexts in the first place, those Dutch speakers who do, require its addressee to be part of the group that the pronoun is generalizing over. To illustrate this point, witness the examples in (10), which produced a strong and uniform judgement among those speakers who accept a strong pronoun in generic contexts:

(10) Context: Two people are talking about a specific company which has been accused of treating employees differently, depending on their gender. One person says to the other:

a. Als jij een vrouw bent, moet je harder werken.

if you $_{\text {strong }}$ a woman are must you harder work

'If you are a woman, you have to work harder.'

\footnotetext{
10 An anonymous reviewer raises the following question: Since a $\phi P$ itself can also refer indexically, why would a pronoun with a D-layer ever appear unless required by certain syntactic structures? First of all, if we take for granted that D-pronouns exist, there is no a priori reason not to use them even if not syntactically required. As for Dutch specifically, this amounts to the question why a strong pronoun would be used in cases where a weak pronoun would suffice. The reasons may thus range from information packaging issues to stylistic or personal preferences.

11 In their follow-up paper, Déchaine and Wiltschko (2010) claim that mere $\phi$ Ps exclude indexical readings, i.e., that only full DPs can be interpreted indexically. I will return to this issue in Sect. 5.1.

12 As already mentioned in Sect. 2, the use of a second person pronoun in generic contexts has been shown to evoke empathy from the addressee (cf. Malamud 2012). It is therefore only natural to assume that the addressee still gets picked out via the relevant $\phi$-feature.
} 
b. Als jij een man bent, moet je harder werken. if you $_{\text {strong }}$ a man are must you harder work 'If you are a man, you have to work harder.'

The crucial observation is that (10a), under the relevant reading where the sentence generalizes over all women in the company, can only be uttered when the addressee herself is a woman. (10b) can only be uttered addressing a man. If one wanted to express the same meaning but were talking to someone of the opposite group, one would have to use the sentence in (11), employing the weak pronoun 'je':

(11) Uttered to a woman:

Als je een man bent, moet je harder werken.

if you weak a man are must you harder work

'If you are a man, you have to work harder.'

I propose that only (11) is a true instance of a generic sentence: it generalizes over a group of people and the addressee is invited to empathize with this group, ${ }^{13}$ irrespective of whether he or she is part of that group. Strong pronouns, on the other hand, refer to the addressee and, if the interpretation does get extended via pragmatics, they make a statement about the addressee as part of a specific group. Thus they are not true instances of generic second person pronouns. Rather, they designate a prototypical referent of a specific group, namely the addressee of the utterance, and only thereby allow it to extend the interpretation of the sentence from the addressee to said group. ${ }^{14}$

Returning to the structural analysis, I will add one last note on spell-out. As for the actual mapping of the pronouns onto the structure, I assume that in principle spell-out has one of two options: it can either target the phrasal level, i.e., an entire XP, or it can target the terminal level, i.e., spell-out individual heads (Weerman and EversVermeul 2002; Neeleman and Szendröi 2007; Barbiers et al. 2009). I propose that Dutch pronouns are subject to phrasal spell-out as schematized in (12).

(12) a.

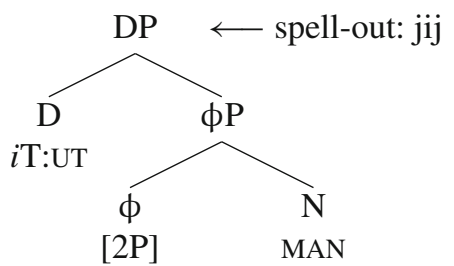

b.

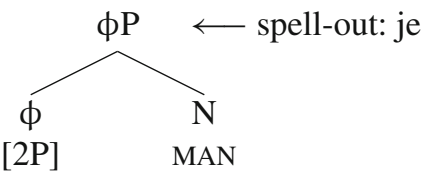

\footnotetext{
13 The empathy-effect of second person pronouns in generic contexts has been demonstrated by Malamud (2012).

${ }^{14}$ I owe this suggestion to Sjef Barbiers, p.c.
} 


\subsection{Further support}

Additional support for an analysis of the strong pronoun 'jij' as a DP comes from equative copular constructions: it has long been noticed that equations differ from predicative structures in many respects (Williams 1983; Partee 1987; Geist 2007). One crucial difference that directly bears on the present discussion concerns the type of arguments that appear in these constructions; witness the examples in (13):
a. Cicero is Tully.
[equation]
b. Cicero is an orator and philosopher.
[predication]

(Geist 2007:87)

Even though the structures of these two sentences are superficially the same, the meaning of the two sentences is crucially different: whereas the first asserts that Cicero and Tully have one and the same referent, the second attributes the property of being an orator and philosopher to Cicero. Importantly, the first example contains two definite noun phrases, whereas the second example contains only one definite and an indefinite noun phrase. Furthermore, predicative structures can contain any type of argument that expresses a property: for instance, instead of the indefinite noun phrase the sentence could also contain an adjective (e.g., 'old'), a prepositional phrase (e.g., 'in the arena'), or an adverbial (e.g., 'here'). None of these options are available in equations: they always only allow two fully referential arguments, specifically two DPs. With this in mind, witness the Dutch sentences in (14): ${ }^{15}$
a. (Ik ben ik en) jij bent jij.
(I am I and) you are you
b. * (Ik ben ik en) jij bent je.
(I am I and) you are you

As these sentences show, only the strong pronoun 'jij' is grammatical in an equation context, whereas the weak pronoun 'je' is ungrammatical. This is in line with my proposal about the internal structure of these pronouns since equations only allow DPs. ${ }^{16}$

\footnotetext{
15 A reviewer suggests that the requirement to use 'jij' rather than 'je' might be due to a need for parallel structures in the conjuncts. However, the first conjunct 'Ik ben ik' is solely given to create a more natural context for the second conjunct, and the grammaticality judgement does not bear on the presence of the first conjunct. The reviewer further suggests that the pronoun might have to be strong due to the need to bear focal stress. This is in fact not correct, the equation context does not require stress. Additionally, although I do not discuss first person pronouns in this paper, I assume that the weak first person pronoun ' $\mathrm{k}$ ' is also not a full DP. This immediately explains why it is also ungrammatical in an equation context and needs to appear as the strong form 'ik'. Another reviewer suggests that weak pronouns might be banned from sentence-final positions on prosodic grounds. Again, this is not the case as evidenced by sentences such as Wat voel je? 'What do you feel?'.

16 One reviewer points out that weak pronouns are also incompatible with predicative readings. However, the situation is more complex in predicative structures than in equations: while strong pronouns seem to be acceptable (cf. 'Just be you.'), reflexives appear to be the more natural choice (cf. 'Just be yourself.'). In any event, the properties of predicative structures are orthogonal to equative sentences.
} 


\subsection{The contribution of $D$}

Having established the morphosyntactic status of 'jij' and 'je', the next question is the following: What does D bring to the table that forces an indexical reading?

The first crucial ingredient is the basic function of D: As in Bliss and Gruber (2015), I follow Gillon (2006) who argues on the basis of data from the Salish language Skw $\underline{x} w u$ 7mesh (Squamish), which has an elaborate system of determiners, that D is universally associated with domain restriction. To briefly illustrate domain restriction in general, consider the sentence in (15):

(15) The girls are exceptionally smart.

Even though this sentence does not contain any explicit restriction on the girls that are being talked about, it is still not about every single girl in the whole world. Rather, it is about a contextually salient set of people, for instance, all my nieces. Essentially, this is due to domain restriction as extensively discussed in, for example, Barwise and Cooper (1981), Westerståhl (1984), von Fintel (1994), Martí (2003) and Etxeberria Otaegi (2005). In short, domain restriction ensures that only the contextually relevant set is interpreted. ${ }^{17}$ Based on her detailed discussion of the determiner system of Skwxwú7mesh, Gillon (2006) argues that universally the semantic function of domain restriction is strictly tied to a specific syntactic position: "Domain restriction is only introduced by D-determiners." (Gillon 2006:3). In particular, she proposes that

D-determiners always introduce domain restriction over their NP, regardless of what other properties they may have. Their function is to constrain the set introduced by the NP to a set of contextually salient individuals.

[Gillon 2006:53]

The universal semantic core of D is thus to restrict the interpretation to the contextually relevant set of entities. ${ }^{18}$ If we now accept both the universal association of D with domain restriction and the idea that pronouns can be full DPs, this immediately raises the question how domain restriction would apply to indexical pronouns: since their referents are directly context-dependent, there is rarely a need to pick them out from a potentially larger set of individuals. ${ }^{19}$ It is proposed that what allows us to maintain Gillon's (2006) basic analysis of D and also apply it to personal pronouns is an ontology that contains both individuals and stages of individuals, as proposed by Carlson (1980) and applied to the interpretation of noun phrases by Musan (1995). ${ }^{20}$

\footnotetext{
17 Note that the determiner-less version of the sentence is not contextually restrictable to a particular set of girls. Rather, it is interpreted generically.

18 Other functions that are often discussed in connection with determiners, such as familiarity (e.g., Heim 1982) or uniqueness (e.g., Kadmon 1992), are taken to arise for independent reasons and not because they are a property of D. For details see Gillon (2006).

19 As an anonymous reviewer points out, domain restriction can also be achieved with relative clauses. An example s/he gives is: 'You who want to come on the trip ...' as an alternative version of 'For those of you who want to come on the trip ...'.

20 Both Carlson (1980) and Musan (1995) consider kinds to be a third type of entity in their ontology. However, this is irrelevant for the issue at hand and hence set aside.
} 


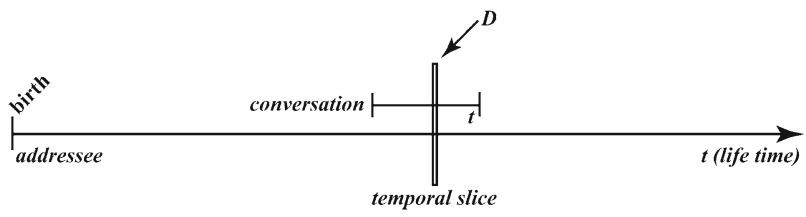

Fig. 1 Domain restriction by UTTERANCE TIME

Assuming that both individuals and stages of individuals are part of the set of available entities, Musan argues that

determiner quantification is not quantification over individuals in their whole temporal extendedness but quantification over STAGES OF INDIVIDUALS.

[Musan 1995:94]

But whereas Musan suggests a purely semantic analysis to account for how the relevant restriction is achieved, syntax is suggested to be crucially involved in the process. Applying her basic insight to indexical pronouns allows us to also take stages of speaker and hearer into consideration and add a temporal component to the pronoun's structure. Further developing this idea from Bliss and Gruber (2015), I propose that $\mathrm{D}^{0}$ contains a TIME-feature that restricts the pronoun's interpretation. Combining this with Gillon (2006) consequently leads to the following result: the stage of the individual denoted by $\phi \mathrm{P}$ that $\mathrm{D}^{0}$ picks out gets determined by the temporal specification located in $\mathrm{D}^{0}$. Conversely, $\phi \mathrm{Ps}$ lacking the temporal restriction denote the individual in its entire temporal extendedness.

We now need to take one final step in order to be able to know which temporal stage gets picked out: we need to determine how and from where TIME in pronominal $\mathrm{D}^{0}$ gets its specification. First of all, we expect the value to be linked to UTTERANCE TIME: Since the data introduced earlier clearly show that one class of pronouns can only ever be interpreted indexically and since indexicality is intrinsically and by definition tied to the utterance context, only UTTERANCE TIME can provide the necessary feature that forces an indexical interpretation of pro-DPs. Note here that although TIME in $\mathrm{D}^{0}$ forces an indexical reading it is not responsible for identifying the addressee: the identification of the referent proceeds via a second person feature in $\phi P$. The function of TIME in $\mathrm{D}^{0}$ is to restrict the referent further to the temporal slice present at the relevant TIME. In the absence of the D-layer, the addressee is referenced in its entire temporal extendedness. With respect to restriction to UTTERANCE TIME, the idea of temporal restriction versus temporal extendedness is illustrated in Fig. 1. ${ }^{21}$

Second, I propose that this specific temporal information is provided by the syntax. I analyse TIME in $\mathrm{D}^{0}$ as an interpretable but unvalued feature in the sense of Pesetsky and Torrego (2007). Unvalued refers to the fact that the pronominal structure has a predefined slot for TIME but no predefined content: since the actual TIME differs from

\footnotetext{
21 Given the assumption that first person pronouns look like second person pronouns, an anonymous reviewer raises the question why generic readings of first person pronouns are not available. However, while not as common as generic interpretations of second person pronouns, first person pronouns may well be interpreted generically. Such cases have been discussed for instance by Kitagawa and Lehrer (1990), Zobel (2010) and Gruber (2013). For the purposes of this paper, I restrict the discussion to second person cases only.
} 
utterance to utterance, the specific value of the feature can only be known once the pronoun is used, i.e., enters syntactic derivation. Consequently, the source of the value must be located elsewhere in the syntax.

Along with a long list of researchers, I assume that utterance-related information is located in Spec-TP (cf. Enç 1987; Stowell 1995, 2007; Demirdache and UribeEtxebarria 2000; Ritter and Wiltschko 2009, 2014). Specifically, following Ritter and Wiltschko (2014), I propose that Spec-TP contains a pronominal situation variable pro-SIT whose default temporal interpretation is utterance time. In other words, there is no actual UTTERANCE TIME-feature encoded in the syntax which could be found by an agreement-seeking TIME-feature in the indexical pronoun's D-position. ${ }^{22}$ However, I assume that UTTERANCE TIME will always be the default value for any TIME-feature. Therefore, the unvalued TIME-feature in pronominal $\mathrm{D}^{0}$ probes upwards to look for a suitable goal: Since it cannot find a valued TIME-feature, it simply receives the default value UTTERANCE TIME (UT). This is then another case of fallible agreement as proposed by Preminger (2011). ${ }^{23}$ One such detailed derivation is given in (16). ${ }^{24}$

$$
\begin{aligned}
& \text { a. Jij leerde het gedicht. } \\
& \text { you } \text { strong }_{\text {learned the poem }} \\
& \text { 'You indexical learned the poem.' }
\end{aligned}
$$

b.
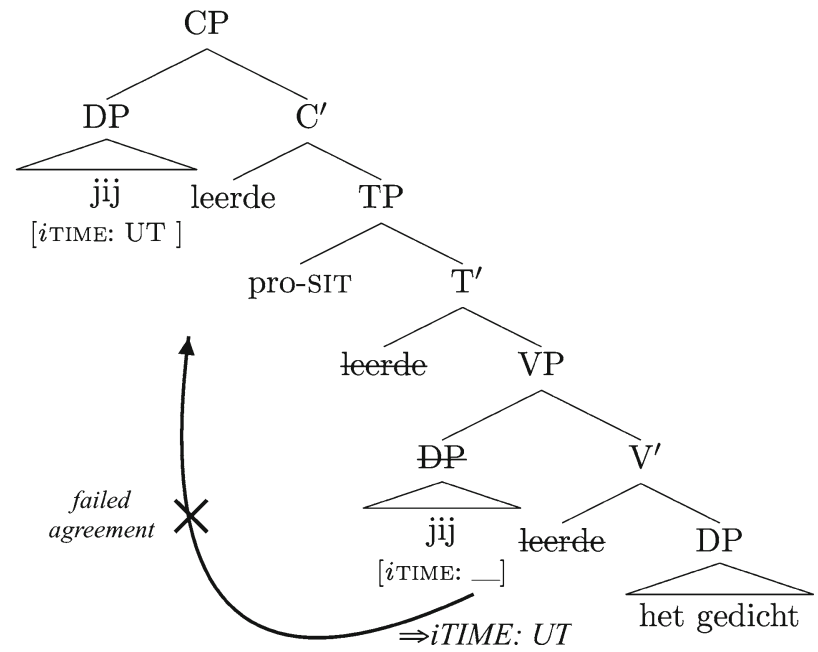

\footnotetext{
22 Along with Wurmbrand (2012a,b) I assume Reverse Agree, i.e., upwards probing for goal-seeking.

23 An alternative analysis would be to simply assume that Dutch second person pronouns have an unvalued UTTERANCE TIME feature in $\mathrm{D}^{0}$ instead of a simple TIME-feature. However, since this analysis is couched in a larger research project that includes crosslinguistic variation beyond pronouns restricted by UTTERANCE TIME, this option is not further pursued. More details on crosslinguistic variation and how it ties in with the analysis presented in this paper are discussed later on in this section as well as at the end of this paper.

${ }^{24}$ For expository reasons only, I follow Stowell (2007) in assuming that the subject bypasses Spec-TP and moves directly to Spec-CP. I also abstract away from little $\nu \mathrm{P}$ as the licenser of the external subject (Kratzer 1996; Chomsky 1995).
} 
At this point, a brief note on the broader picture of this analysis is in order: Generally, I follow several researchers in assuming that TIMEs are syntactically represented as referential expressions (e.g., Enç 1987; Zagona 1990; Stowell 1995, 2007; Demirdache and Uribe-Etxebarria 2000). Along with utterance-related information in Spec-TP, EVENTUALITY TIME is taken to be encoded within the VP (cf., e.g., Enç 1987; Zagona 1990; Stowell 1993, 1995, 2007; Demirdache and Uribe-Etxebarria 1997, 2000, 2007). Consequently, both TIMEs are potential candidates for defining the specifications of TIME in the indexical's D-position. I suggest that whether a pronoun in a given language uses the default UTTERANCE TIME or agrees with EVENTUALITY TIME in VP is subject to parametric variation. Thus a Dutch second person pronoun in an infinitival clause will not consider the EVENTUALITY TIME argument of the matrix clause a suitable goal.

\section{What about German and English?}

Both German and English can also use a second person pronoun in generic contexts. The following example, already given in (2), illustrates this for English and German, respectively.

(17) a. In the 19th century, you could often meet famous artists in cafés in Vienna.

b. Im 19. Jahrhundert konntest du in Wien oft berühmte Künstler in.the 19th century could you in Vienna often famous artists in den Kaffeehäusern antreffen.

in the cafés meet

'In the 19th century, you could often meet famous artists in cafés in Vienna.'

However, as opposed to Dutch, the standard varieties of these two languages only have one set of pronouns each. In what follows, I present the analysis for Standard German and English second person pronouns and discuss further evidence that supports this account.

\subsection{The analysis of German and English 'you'}

In the previous section, I argued that Dutch weak and strong second person pronouns map onto two different syntactic structures: whereas the weak indexical pronoun lacks the DP-projection, the strong indexical pronoun corresponds to a complete DPstructure. The latter thus contains temporal specification that restricts the interpretation of the pronoun to a specific temporal stage, namely that of UTTERANCE TIME.

I propose that Standard German 'du' as well as Standard English 'you' can be realized as either a full DP structure or simply a $\phi P$. In other words, although Standard English and German do not distinguish between two different morphophonological forms, morphosyntactically they can still map onto two different structures. ${ }^{25}$ If the

\footnotetext{
25 The relationship between the two different forms is orthogonal to the present analysis. While it is logically possible that there are two homophonous lexical entries, I will assume that the forms are derived from a single lexical entry. This could be due to either underspecification or derivation.
} 
pronoun appears within a generic statement, as in (3), and receives a non-indexical interpretation, it follows from my account that we are dealing with a $\phi P$, i.e., a structure with no temporal restriction on its interpretation. As the German and English surface forms are identical and pro- $\phi$ Ps can refer both generically and indexically, this naturally raises the question why English and German should have a pro-DP in the first place. There are two main arguments for this claim.

First of all, there are cases in which a second person pronoun can only be interpreted indexically. In (18), no ambiguity arises and I conclude that we are dealing with a full DP. In the example, capitalization indicates focal stress.

(18) Context:Verena always catches a cold as soon as the temperature drops. She sees her sister Mirjam leaving the house on a cold day in nothing but a miniskirt and a T-shirt. Verena tells her to put on a coat. Mirjam, who never gets sick, replies:

If YOU leave the house in the winter, you have to put on a coat. I, however, don't have to do that.

With the given context, this contrastively focalized second person pronoun in the first sentence can only get one interpretation, namely that of an indexical. Again, these English data are paralleled in Standard German. Importantly, the non-focussed counterpart in both languages, given in (19), is ambiguous between a generic and an indexical interpretation:

(19) a. If you leave the house in the winter, you have to put on a coat.

b. Wenn du im Winter außer Haus gehst, musst du einen Mantel if you in.the winter out.of house go must you a coat anziehen.

put.on

Secondly, German and English second person pronouns can also appear in equations which always require two DPs, as already discussed in Sect. 3.2. This is illustrated in (20a) for English and (20b) for German:

(20) a. You are Sophia.

b. Du bist Sophia. you are Sophia

This, of course, is reminiscent of the Dutch data we saw earlier: in one case a second person pronoun is restricted to an indexical interpretation, while in the other case it is potentially ambiguous between an indexical and a generic reading. The crucial piece of information for the present discussion is the fact that also in English and German we find both pragmatic and syntactic contexts in which a pronoun can only be interpreted indexically. From this I conclude that the second person pronoun in (18) must be a DP containing domain restriction to a temporal slice and forcing an indexical interpretation. Conversely, the generic cases must be $\phi P$ s since they are bound by a generic operator. Therefore I propose that both English 'you' and German 'du' can be realized as either of the two structures depicted in (21) and are thus structurally ambiguous. 
(21) Both underlying structures of 'du'/'you':

a.

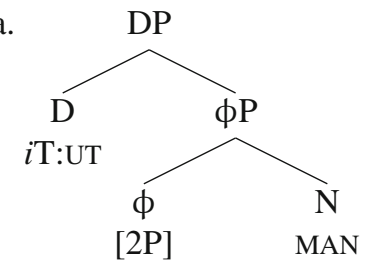

b.

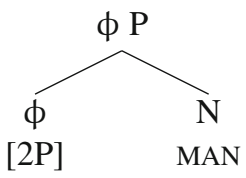

Again, just as in Dutch, spell-out targets the phrasal and not the terminal level. Note that the claim is not that English and German have both a weak and a strong second person pronoun. Clearly, the Standard varieties of both languages only have one single morphophonological form. Instead, I argue that underlyingly they can be realized as two different structures. This claim is also supported by the following example which at first seems to contradict the previous geneneralization (cf. also Bolinger 1979): ${ }^{26}$

(22) a. In the States you generic hire someone to do your generic $_{\text {gaxes. }}$

b. In Europe, $\mathrm{YOU}_{\text {generic }}$ have to do them.

Here, a focused second person pronoun clearly gets a non-indexical, generic interpretation: people in Europe have to do their taxes themselves. ${ }^{27} \mathrm{I}$ argue that this is possible precisely because English (and German) does not distinguish between weak and strong pronouns but still has both a pro- $\phi \mathrm{P}$ and a pro-DP second person pronoun: whereas the ability to bear stress is tied to the morphophonological form, the ability to refer generically is tied to the underlying morphosyntactic form. Note that the Dutch equivalent of (22b) can only employ the weak pronoun 'je', i.e., the one lacking a temporal restrictor, and thus the pronoun cannot bear stress. Instead, Dutch would use the reflexive 'zelf' for emphasis (23):

(23) In Europa moet je het zelf doen.

in Europe must you it self do.

The ability to bear stress is thus detached from the question of generic or indexical reference, as summarized in Table 3.

In sum, I do not assume a fixed correspondence between the ability to bear stress and the underlying structure. $\phi P s$ may well be able to bear stress in some languages

\footnotetext{
26 I owe this example to Hotze Rullman (p.c).

27 A reviewer points out that in a conditional environment stressed pronouns may also refer generically. S/he gives the following example:
}

(i) In Italy, people always speak badly about their politicians, but if YOU do, they'll be cross.

However, it has often been noted that generic sentences are similar to conditionals (cf. Krifka et al. 1995 and references therein); in fact, Heim (1982) even treats them alike semantically by arguing that both contain modal quantification. Thus the example (22b) can easily be restated as a conditional without any change to its meaning: If you live in Europe, YOU have to do them. The reviewer further points out that the same is not possible if the pronoun gets replaced by a noun like 'people'; while it appears to be impossible to simply replace stressed 'you' with stressed 'people', the following is easily possible: In Europe, people have to do them themselves. This ties in with the observation that in any case a lot of speakers prefer a reflexive for emphasis, also in (22b). 
Table 3 Distribution of phonological and semantic properties

\begin{tabular}{llllll}
\hline & & & Stress & Generic & Indexical \\
\hline \multirow{2}{*}{ English } & you & pro- $\phi P$ & $\checkmark$ & $\checkmark$ & $\checkmark$ \\
\multirow{2}{*}{ Dutch } & you & pro-DP & $\checkmark$ & - & $\checkmark$ \\
& je & pro- $\phi P$ & - & $\checkmark$ & $\checkmark$ \\
& jij & pro-DP & $\checkmark$ & - & $\checkmark$ \\
\hline
\end{tabular}

but not in others. Likewise, we cannot draw conclusions about the internal structure of a pronoun solely by looking at its morphophonological properties (cf. Déchaine and Wiltschko 2002). ${ }^{28}$ Instead, I assume that morphophonological weight is the key factor in a pronoun's ability to bear stress. Even though neither the English nor the German surface form can tell us which of the two underlying structures we are dealing with, the linguistic context helps us distinguish between the two forms. Interestingly, some varieties of English actually do have a phonologically weak second person pronoun 'ya' and a strong form 'you'. Preliminary evidence points to them corresponding to $\phi P$ and DP structures, respectively: only 'ya' seems to be able to receive a generic reading, whereas 'you' appears to be restricted to indexical interpretations, as also briefly mentioned in Jackendoff (2007). This issue is, however, still subject to further empirical inquiry.

\subsection{Further support: restrictions on generic second person pronouns}

It is well known that the German impersonal pronoun 'man', which can also receive a generic interpretation, can only appear as a nominative subject, but never as an object. Instead, German speakers have to resort to other strategies to convey the desired meaning, such as the indefinite einer 'one'. This is illustrated in the examples in (24):

(24) Context: Friends are discussing the hierarchy of a big company. One of them claims that the vice president doesn't have the authority to actually fire employees. Another one replies:

a. Der Vizepräsident kann einen ganz sicher feuern. the vice.president can one total sure fire

'The vice president can definitely fire people.'

b. * Der Vizepräsident kann man ganz sicher feuern. the vice.president can man total sure fire

However, the same is clearly not true for a second person pronoun which happily appears as the direct object $(25):^{29}$

\footnotetext{
28 While Déchaine and Wiltschko (2002) do propose that DPs are morphologically more complex than $\phi P s$ which in turn are morphologically more complex than NPs, this only seems to hold when there is a morphological containment relation. It is well possible that a language has a pro-DP that is phonologically lighter than a pro- $\phi P$. This is in fact proposed by Déchaine and Wiltschko (2002) for English: they analyse 'we' as a pro-DP and 'they' as a pro- $\phi P$.

29 See Egerland (2003) for the same point with respect to the grammaticality of generic second persons in both subject and object position in Swedish, French and Italian.
} 
(25) Der Vizepräsident kann dich ganz sicher feuern. the vice.president can you. ACC total surely fire

'The vice president can definitely fire you.'

Again, this sentence can get both an indexical and a non-indexical reading, i.e., it is on par with all the other examples that we saw earlier, in which a second person pronoun can receive a generic interpretation. Likewise, a generic second person pronoun can appear as the indirect object (26), in reflexive constructions (27), within a prepositional phrase (28), and as a possessive (29):

(26) Österreich gibt dir kein Stipendium, wenn du über 35 bist. Austria give you.DAT no stipend when you over 35 are 'Austria doesn't give you a stipend once you are over 35.'

(27) Als junger Mitarbeiter musst du dich immer extra anstrengen. as young employee must you yourself always extra apply 'As a young employee, you always have to really apply yourself.'

(28) Gute Freunde fühlen mit dir, auch wenn du weit weg lebst. goodfriends feel with you.DAT also if you far awaylive 'Good friends sympathize with you, even if you live far away.'

(29) Heutzutage musst du wirklich hart arbeiten, um deine Familie zu ernähren. nowadays must you really hardwork to your family to feed 'Nowadays, you really have to work hard to feed your family.'

Argument positions therefore do not pose a challenge for second person pronouns in generic contexts, neither in German nor in English, as can be seen from the translations of each of the previous examples. But now consider the examples in (30):

a. Auf dem Land gehst du jeden Sonntag in die Kirche. on the country go you every Sunday in the church 'In the countryside, you go to church every Sunday.

b. Auf dem Land gehen du und deine Familie jeden Sonntag in die on the country go you and your family every Sunday in the Kirche. church 'In the countryside, you and your family go to church every Sunday.'

Whereas the first sentence in (30a) is just like any other example that supports both an indexical and a generic interpretation, in (30b) only the indexical interpretation of the second person pronoun is possible. If one wants to express this sentence as a generic statement the coordinated argument has to be replaced, for instance by a comitative as in (31).

(31) Auf dem Land gehst du jeden Sonntag mit deiner Familie in die Kirche. on the country go you every Sunday with your family in the church 'In the countryside, you go to church every Sunday with your family.' 
Now the coordinated phrase is replaced by a second person subject and a prepositional phrase; once again, both a generic and an indexical reading are available. Note at this point that again the same holds for the English translations of all these examples. This reminds one of the well-known fact that weak elements are generally excluded from coordinated structures (cf. Kayne 1975; Holmberg 1986; Cardinaletti and Starke 1999). As expected then, the Dutch weak pronoun ' $\mathrm{je}$ ' is impossible in the equivalent of (30b), only the strong pronoun 'jij' is licit in this context, as shown in (32a), ${ }^{30}$ and again the generic interpretation can only be achieved with a comitative (32b):

a. Op het platteland gaan *je/jij en je gezin iedere zondag naar de on the country go you and your family every Sunday to the kerk.

church

'In the countryside, you and your family go to church every Sunday.'

b. Op het platteland ga je iedere zondag met je gezin naar de kerk. on the country go you every Sunday with your family to the church 'In the countryside, you go to church every Sunday with your family.'

These data support my analysis of Standard German and Standard English second person pronouns along the same lines as Dutch indexical pronouns: even though the former do not have weak and strong pronouns, second person pronouns in coordinated structures are pro-DPs, and hence obligatorily indexical. Likewise, none of these three languages allow topicalization of the generic pronoun, as shown in (33). Again, these must all be cases of pro-DPs.

a. Dich kann der Vizepräsident auf jeden Fall feuern. you can the vice.president on every case fire

'You ${ }_{\text {indexical }}$, the vice president can fire in any case.'

not: 'The vice president can fire someone in any case.'

b. Jou kan de vice-president in elk geval ontslaan.

you can the vice.president in any case fire

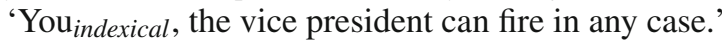

not: 'The vice president can fire someone in any case.'

English and German second person generic pronouns thus behave like weak elements which have been shown to be excluded from both coordination and topicalization (Kayne 1975; Holmberg 1986; Cardinaletti and Starke 1999).

To summarize, no restrictions apply to second person generic pronouns with respect to the type of syntactic argument they express. They can freely appear as subjects, direct objects, indirect objects, reflexives, and possessives. ${ }^{31}$ However, there are restrictions

\footnotetext{
30 'Je' in the second coordinate in (32a) is a possessive second person pronoun and the whole coordinate [je gezin] is again a DP.

31 In this section, I have illustrated the lack of syntactic restrictions for German and English. With respect to the crosslinguistic validity of this observation, the questionnaire distributed for this research contained examples with second person in direct object position and as a possessive. None of the cases in which second person was accepted as a generic in principle showed any significant sensitivity to syntactic position. It seems to hold crosslinguistically that once a second person pronoun can receive a generic interpretation, it can do so in any syntactic position. See also Egerland (2003) for a similar conclusion.
} 
with respect to coordinated structures and topicalization: if second person pronouns appear in either structure, they are necessarily interpreted indexically. From this I conclude that in those cases we are dealing with full DPs.

\subsection{Genericity and temporality}

As mentioned earlier, there is a principled distinction between generic and episodic sentences. Whereas generic statements report general facts about individuals and events, as in (34a), episodic sentences report specific events, as in (34b):

a. Cats sleep most of the day.

b. My cat slept on the armchair last night.

This distinction is relevant to the behaviour of second person pronouns: whereas they can be ambiguous between an indexical and a generic interpretation in generic sentences, as in (35a), no such ambiguity can arise in episodic statements, as in (35b):

a. In Wien frühstückst du im Kaffeehaus.

in Vienna have.breakfast you in.the café

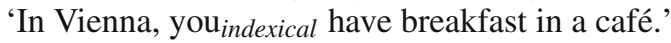

also: 'In Vienna, one has breakfast in a café.'

b. Du bist in ihr Haus eingebrochen.

you are in their house in.broke

'You ${ }_{\text {indexical }}$ broke into their house.'

It has often been observed that generics have an "omnitemporal or atemporal character in that they do not speak of any particular time at all" (Carlson 1980:273). ${ }^{32}$ Episodic statements, on the other hand, not only permit specific time reference; given that they report specific events, they necessarily include temporal reference, be it explicitly by virtue of an adverbial phrase or implicitly by virtue of a contextually salient temporal location.

This atemporality of generics is naturally reflected in the requirement for atemporality of indexical pronouns in generic contexts: whenever a second person pronoun refers generically, it must not contain a TIME-feature which equals specific temporal reference. This feature precludes generalizing from the addressee to people in general. While it is not the case that generic statements generally disallow explicit temporal reference (cf. 'In the '70s, tomatoes were tasty'), the fact that they report generalizations over events implies that they refer to more than a single, time-bound occurrence of an event. Importantly, genericity in the cases of interest here pertains not only to the sentential level but also to the pronominal level: we are not only generalizing over events but we are generalizing over people in those events. Consequently, the generic operator GEN also needs to quantify over the pronoun and thus only pronouns that are variables, i.e., do not have a D-layer, are possible in these contexts. It is therefore the

\footnotetext{
32 One reviewer raises the question of how an indexical pronoun can value its TIME-feature considering that generics are atemporal. However, this atemporality does not include UTTERANCE TIME, since naturally generic sentences will also have an actual time of utterance.
} 
interaction of internal and external syntax that makes it possible for a second person pronoun to receive a non-indexical interpretation: the external environment induces the generic interpretation by means of the adverbial quantifier GEN, while the internal syntax facilitates such a reading due to the lack of temporal anchoring to the utterance time.

To sum up, I argue that the same structures are available in English, German, and Dutch: first and second person pronouns can either be $\phi$ Ps or DPs and the latter can only be interpreted indexically. But whereas Dutch differentiates these structures overtly in its morphosyntax, Standard English and Standard German do not: both languages assign one and the same morphophonological string to both underlying structures; which of the two structures is being used can only be determined by looking at the (un)available interpretations.

\section{Beyond generic readings}

There are at least two more uses of second person pronouns that do not (only) reference the addressee which provide an interesting testing ground for the analysis outlined above: bound variables and speaker-oriented uses. Both of these phenomena will be discussed in turn below.

\subsection{Bound variables}

It is a well-known fact that English indexical pronouns can be used as bound variables, a fact that prima facie is unexpected of indexical items and hence has given rise to several discussions in the literature (see Partee 1989; Kratzer 1998, 2006; Rullmann 2004). A standard example is given in (36):

(36) I hope that I will win, but of course you do too.

(Rullmann 2004:162)

Under the strict reading, 'you' also hope that 'I' will win; under the sloppy bound variable reading, 'you' hope that 'you' will win. In a follow-up to their 2002 paper, Déchaine and Wiltschko (2010) discuss these facts and based on Reinhart (1983), they propose the diagnostic in (37) for identifying the class of bound variables:

(37) The bound variable diagnostic

If $\alpha$ is a local domain form then $\alpha$ is a bound variable.

(Déchaine and Wiltschko 2010:6)

In this diagnostic, local domain form refers to the specific morphological form that a locally bound expression takes on. In classical binding theory, this was defined as an anaphor; however, it has been shown that there is considerable crosslinguistic variation in the sense that not every language has dedicated anaphors but may employ other expressions instead. For instance, whereas English has such a dedicated form, i.e., the reflexive in (38a), French uses a regular pronoun in the very same environment, (38b): 
(38) a. I admire myself.

$\lambda x[x$ admires $x]$

b. Je m' admire.

1SG.NOM 1SG.ACC admire

'I admire myself.' (lit.: I admire me.) $\lambda x$ [x admires $x]$

(Déchaine and Wiltschko 2010:5)

Both the English 'myself' and the French 'm(e)' are thus local domain forms in Déchaine and Wiltschko's (2010) sense: they are both locally bound and are thus identified as bound variables. In their account pro-DPs are intrinsically indexical and pro- $\phi$ Ps are variables. Consequently, for them both English 'myself' and French 'me' map onto $\phi P s$. Conversely, forms that map onto a full DP are necessarily indexical and cannot function as local domain forms, i.e., they cannot be locally bound. Just like in the analysis outlined in this paper, they also conclude that English personal pronouns can therefore be either a $\phi \mathrm{P}$ or a DP.

The crucial difference between their conclusion and the one argued for here is the following: Déchaine and Wiltschko (2010) propose that person features are associated with $\mathrm{D}$ in indexically referring pronouns, whereas they are associated with $\phi$ in local domain forms. They arrive at this conclusion based on the data in (39) with the accusative pronoun 'me'. However, the analysis extends to nominative forms as well, since they can also appear as both indexical and bound variable pronouns.

(39) a. Everyone suspects $\left[{ }_{D} \mathbf{m e}\right]$.

b. $\forall \mathrm{x}$ ( $\mathrm{x}$ suspects SPEAKER)

c. Even $[\phi \mathrm{I}]$ suspect $\left[{ }_{\phi} \mathbf{m e}\right]$.

d. $\lambda x(x$ suspects $\mathrm{x})$

The structures (Déchaine and Wiltschko 2010) associate with these pronouns then look as given in (40).

(40) a. indexical first person: 'me' (39a)

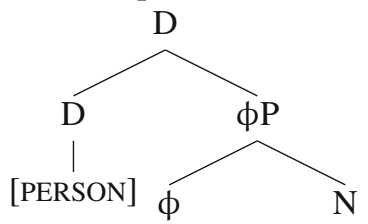

b. bound variable (=non-indexical) first person: 'me' (39c)

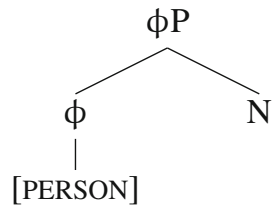

Thus the main difference between their analysis and the one developed here is that in my proposal person-features are intrinsically associated with $\phi$ and that hence $\phi P s$ can refer indexically without a dominating D. Déchaine and Wiltschko (2010), on the 
other hand, allow for $\phi$-features to associate with either $\phi$ or with D. According to them, if $\phi$-features associate with $\mathrm{D}$, the pronoun refers to a speech act participant. If they instead associate with $\phi$, the pronoun behaves like a variable and can thus be bound. This analysis is problematic for two reasons: first, Déchaine and Wiltschko (2010) explicitly expect to find languages that associate specific morphology with each head within the pronominal structure. They refer to this as "additive morphology". If then only a $\phi \mathrm{P}$ gets spelled out, then we also only find the morphemes associated with $\phi$. But if a DP gets spelled out, then we get the morphology associated with D stacked on top of the morphology associated with $\phi$, which is illustrated in (41):
a. [фP y]: spell-out y

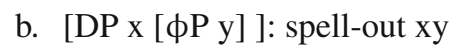

However, it remains unclear how additive morphology could come about: if each head adds its own spell-out to the pronoun, then we expect this spell-out to also be associated with the features located in the respective head. But if it is indeed the case that personfeatures associate with $\mathrm{D}$ in indexical pronouns, but with $\phi$ in non-indexical ones, then it is unclear what $\phi$ spells out in cases of indexical DPs when a language does indeed display additive morphology. Second, the analysis does not account for the fact that we observe ambiguity in the bound variable data they discuss, i.e., between strict and sloppy readings. Since $\phi$ Ps cannot refer indexically, the sloppy reading would have to involve an underlying pronominal structure that is different from the one in the strict reading.

With this analysis in mind, I will now turn to Dutch. Recall that I argue that the weak second person pronoun 'je' maps onto a $\phi P$ whereas the strong pronoun 'jij' maps onto a DP. Following Déchaine and Wiltschko's (2010) bound variable diagnostic, we thus expect the weak pronoun to act as a local domain form whereas the strong pronoun should be barred from such a position. This prediction is indeed borne out, as shown by the data in (42) from Reuland (2001):

$$
\begin{aligned}
& \text { a. Jij voelde je wegglijden. } \\
& \text { you felt you weak } \\
& \text { 'You flide.away. } \\
& \text { b. * Jij vourself slide away.' } \\
& \text { you felt you } \quad \text { you } \text { strong } \text { slide.away. }
\end{aligned}
$$

(Reuland 2001:465; glosses adapted, translation added by BG)

As these examples illustrate, the weak second person pronoun can function as the reflexive, i.e., it is a local domain form under the relevant condition; the strong pronoun, on the other hand, is barred from this position, exactly as predicted by my analysis of this form as a DP. Similarly, van Koppen (2012) presents Dutch bound variable data as in (43a) where the weak pronoun in the embedded clause gives rise to both a strict and a sloppy interpretation under ellipsis.

a. Jij voelde dat de vijand je zag en ik ook. you strong felt that the enemy you weak saw and I too 'You felt that the enemy saw you and I did too.' (van Koppen 2012:143) 

b. strict reading: '.. and I also felt that the enemy saw you'
c. sloppy reading: '.. and I also felt that the enemy saw $m e$ '

The interesting piece of data now is the version of this sentence with the strong pronoun 'jij' in its accusative form jou as in (44):

(44) Jij voelde dat de vijand jou zag en ik ook. you $_{\text {strong felt that the enemy you }}$ strong saw and I too 'You felt that the enemy saw you and I did too.'

This type of sentence gives rise to varying judgements: Out of ten speakers that I consulted, six categorically excluded a bound variable reading for the strong pronoun as predicted by my analysis; three considered it possible but only as long as 'jou' was not stressed; and one speaker had no problems getting both a strict and a sloppy reading. ${ }^{33}$ In general, it appears to be the case that strong pronouns strongly favour a strict reading, but sloppy interpretations are available for a non-negligible number of speakers. A similar point is also made in Maier and Schepper (2010) for Dutch and Déchaine and Wiltschko (2002) for French; Rullmann (2004) notes for similar examples in English that:

[S]loppy identity readings of 1 st and 2 nd person pronouns are possible in principle [...], although individual speakers may differ in the extent to which they accept such examples.

[Rullmann 2004:162]

van Koppen $(2005,2012)$ takes the fact that sloppy readings can arise as evidence for the $\phi \mathrm{P}$ status of all Dutch pronouns, irrespective of whether they are weak or strong. However, in light of the evidence put forward throughout this paper, I maintain that strong Dutch pronouns are DPs containing temporal restriction: I have shown that strong pronouns are obligatorily indexical in all instances where weak pronouns are possible and ambiguous between a generic and an indexical interpretation; furthermore, in line with the claim that only $\phi P s$ can function as bound variables, 'je' can function as a reflexive (Reuland 2001) and may also be bound by the generic operator GEN. At this point, I cannot fully account for the fact that some speakers do allow sloppy readings of strong pronouns. However, as pointed out, the acceptance of bound variable readings is subject to considerable speaker variation across languages. Thus I generally doubt that bound variable data involving ellipsis are a suitable predictor of the syntactic status of pronouns. One possible solution was suggested by an anonymous reviewer: For some people focus might be associated with strict identity. Strict identity might then require focus for those speakers (cf. example 18). This would shift the significance of the data from being connected to syntax to being connected to pragmatics. I therefore reject the kind of bound variable readings illustrated in (36) or (43a) as a suitable and reliable diagnostic for the distinction between pro- $\phi$ Ps and pro-DPs and maintain that Dutch 'je' maps onto a $\phi P$ and Dutch 'jij' onto a DP.

\footnotetext{
33 One anonymous reviewer raises the question of whether dialectal variation might be relevant here. While I cannot fully exclude some unconscious dialectal influence on the judgements, speakers were explicitly asked to judge the standard version of the sentence.
} 


\subsection{Second person pronouns referring to the speaker}

Another related phenomenon concerns the interpretation of a second person pronoun as referring to the speaker of the utterance. Such cases have been given particular attention in the literature about Dutch 'je' (cf. Bennis 2004; Zeijlstra 2008).

'Je' can not only give rise to generic readings as shown in this chapter but also to speaker-oriented readings, i.e., 'je' can be interpreted as 'I' instead of 'you', as illustrated in (45). ${ }^{34}$

(45) Je kreeg de bal en toen zag je iemand vrijstaan en toen speelde je you got the ball and then saw you someone free.stand and then played you de bal direct. the ball directly

'You got the ball and then you saw someone stand free and you played the ball directly.'

(Bennis 2004:19, glosses and translation by BG)

This example is taken from an interview with a football player who was talking about himself using the weak second person pronoun 'je'. However, this type of interpretation of a second person pronoun is not limited to Dutch. Consider for instance the example in (46), which was part of the questionnaire that this research is based on (cf. Gruber 2013):

(46) A journalist asks Kate Winslet how she felt when she received the Oscar. She says:

"You are just completely overwhelmed, you can't believe that this is actually happening to you and you are simply very grateful."

Clearly, this statement is not about the journalist who asked the question but about the interviewee who talks about her own experience. The survey conducted for this research showed that this kind of reading is readily available in a number of languages, e.g., Afrikaans, Catalan, German, Modern Greek, Italian, Indonesian, or Chinese, some of which are exemplified below.

(47) Ests completament aclaparat, no pots creuret que aix be.2SG completely overwhelmed, no can.2SG believe.are.2SG.CL that this $\mathrm{t}$ est passant realment a tu i ests simplement molt 2SG.CL be.3SG happening actually to you and be.2SG simply very agrat grateful

'You are just completely overwhelmed, you can't believe that this is actually happening to you and you are simply very grateful.' (Catalan, Indo-European)

\footnotetext{
34 One anonymous reviewer raises the question of adjectival gender agreement and whether it is determined by the speaker or the hearer in these cases. However, first of all Dutch does not show this kind of agreement and second, Dutch only distinguishes between common (masculine and feminine) and neuter gender. Therefore, we do not expect to see any gender effects on adjectives with respect to indexical pronouns.
} 
(48) Den boris na pistepsis oti afto to pragma su simveni ondos! Neg can.2SG SUBJ believe.2SG that this the thing to.you happen really

Ke niothis aperandi evgnomosini.

and feel.2SG endless gratitude

'You cannot believe that this thing is really happening to you! And you feel endless gratitude.'

(Modern Greek, Indo-European)

(49) Anda betul-betul sangat bahagia, anda tidak percaya bahwa ini benar-benar you really very happy you not believe that this really

terjadi pada Anda dan Anda sangat berterima.

happened to you and you very grateful

'You are really very happy, you can't believe that this is really happening to you and you are very grateful.'

(Indonesian, Austronesian)

With respect to my analysis of indexical pronouns, I predict that these cases also resort to the structure lacking temporal anchoring and can hence get an interpretation that targets the speaker herself: at least for Dutch, this prediction is illustrated by such data as in (45) and the fact that the strong pronoun 'jij' is excluded from these contexts (cf. Zeijlstra 2008). As argued for throughout, the strong pronoun necessarily receives an indexical reading and is therefore not only unavailable in generic contexts but also as a reference to the speaker. ${ }^{35}$

From a pragmatic point of view, these examples are similar to generic contexts: the addressee is invited to put herself into the speaker's shoes; in generic contexts, she is invited to put herself into someone else's shoes.

Zeijlstra (2008) also argues that the availability of speaker-reference is structurally conditioned: however, his proposal is based on the idea that the weak pronoun 'je' only carries a feature that encodes speech-act participation; consequently the interpretation can go either way. However, this account does not capture the fact that the default interpretation is still reference to the addressee and that the speaker-referring variation can only be deduced from the context. Furthermore, considering that the phenomenon of second person pronouns referring to the speaker is not unique to Dutch but extends to numerous other languages (see example (46)), it is not clear how Zeijlstra's (2008) account could be extended to all those other languages. To the best of my understanding, extending Zeijlstra's (2008) approach to these languages means that all have a second person pronoun that only carries participant-features and bears no relation to the addressee. This would turn second person pronouns into underspecified pronouns in a wide range of related and unrelated languages. While it is conceivable that, just as proposed here, those languages with only one surface form also have two under-

\footnotetext{
35 One reviewer points out that this implies that second person pronouns in coordinated structures should not be able to refer to the speaker. At least for German this is correct, as the following sentence can only mean that the addressee and his/her colleagues are thrilled and is thus infelicitous in the following context. A journalist asks Kate Winslet how she and the whole film team felt when she received the Oscar. She says:

(i) \#Du und deine Kollegen freuen sich einfach riesig. you and your colleagues be.thrilled REFL simply massively

'You and your colleagues are just massively thrilled.'
}

Whether this applies to other languages, as well, is subject to further empirical research. 
lying structures, they would still all have one structure that is entirely underspecified with respect to its referent. This seems neither conceptually nor empirically desirable. I therefore maintain that my analysis of 'je' is superior, since it not only accounts for the pronoun's default interpretation but also straightforwardly extends to other languages.

A full account for how the speaker-referring interpretation comes about goes beyond this paper but I suggest that the precise mechanism lies outside the realm of syntax. It has been suggested by several speakers of different languages that the choice of the second person pronoun in such cases conveys some kind of modesty on the speaker's part, which strongly suggests a non-negligible pragmatic side of the phenomenon. It therefore seems plausible to assume that these cases are subject to pragmatic inferences that lead to the relevant interpretation, rather than syntactico-semantic processes that influence the interpretation of the pronoun.

\section{Summary and outlook}

In this paper, I argued that Standard English and German second person pronouns can map onto either a full pro-DP or a pro- $\phi \mathrm{P}$ structure while in Dutch the weak pronoun 'je' maps onto a pro- $\phi \mathrm{P}$ and the strong pronoun 'jij' onto a pro-DP. I proposed that D contains an interpretable but unvalued TIME-feature that restricts the interpretation of the pronoun to a contextually relevant temporal stage of the individual denoted in the $\phi P$. In English, German, and Dutch the TIME-feature in D receives the default interpretation UTTERANCE TIME. Since therefore only DPs but not $\phi P$ s contain a restriction to the specific temporal stage of UTTERANCE TIME, only the former but not the latter are obligatorily interpreted as indexicals. I claim that whereas German and English do not show this distinction overtly in their pronominal morphology, Dutch does: the weak pronoun ' je', which can be used in generic contexts, maps on to a pro- $\phi P$ whereas the obligatorily indexical strong pronoun 'jij' maps onto a pro-DP. The temporal component in D provides domain restriction over the individual denoted in the $\phi \mathrm{P}$ : I propose that it picks out a specific temporal stage of that individual and limits the interpretation of the whole structure to this temporal slice. Since English, German, and Dutch indexical pronouns are all argued to be of the parametric type that picks out UTTERANCE TIME, their pro-DPs are all obligatorily indexical.

As briefly mentioned in Sect. 3.3, a system that appeals to syntactically encoded TIMES such as UTTERANCE TIME leads us to expect cases in which other TIMES that are also taken to be represented in the syntax provide the relevant specification for pronouns. This option is taken to be the source of crosslinguistic variation: a given language draws the temporal information that restricts the interpretation of its indexical pronouns from one of the syntactically encoded TIMEs. As such, the next logical option is EVENTUALITY TIME, generally taken to be represented within the VP (cf., e.g., Enç 1987; Zagona 1990; Stowell 1993, 1995, 2007; Demirdache and UribeEtxebarria 1997, 2000, 2007). Further developing work published in Bliss and Gruber (2015), Gruber (2013) shows that one such language is Blackfoot (Algonquian) which consistently uses personal proclitics that lack the D-layer in contexts that do not involve a temporally restricted eventuality (e.g., inalienable possession). However, proclitics 
which do contain a D-layer appear in cases in which the relationship between the individual denoted by the pronoun and the eventuality under discussion is temporally restricted. An open empirical issue at this point is whether there are also languages whose pronouns are restricted by ASSERTION TIME which is argued by Demirdache and Uribe-Etxebarria $(2000,2007)$ to be syntactically represented.

Acknowledgements I am grateful to Alexis Dimitriadis, Martina Wiltschko and three anonymous reviewers for comments on this paper. A slightly different version appeared as chapter 4 in my dissertation (Gruber 2013). As such it owes a lot to many people, most of all to Sjef Barbiers, Norbert Corver, and Marjo van Koppen.

Open Access This article is distributed under the terms of the Creative Commons Attribution 4.0 International License (http://creativecommons.org/licenses/by/4.0/), which permits unrestricted use, distribution, and reproduction in any medium, provided you give appropriate credit to the original author(s) and the source, provide a link to the Creative Commons license, and indicate if changes were made.

\section{References}

Abney, Steven. 1987. The English noun phrase in its sentential aspect. Doctoral Dissertation, Massachusetts Institute of Technology, Cambridge, MA.

Alonso-Ovalle, Luis. 2002. Arbitrary pronouns are not that indefinite. In Proceedings of Going Romance 2000, ed. Claire Beyssade, Reineke Bok-Bennema, Frank Drijkoningen, and Paola Monachesi, 1-14. Amsterdam: Benjamins.

Barbiers, Sjef, Olaf Koeneman, and Marika Lekakou. 2009. Syntactic doubling and the structure of whchains. Journal of Linguistics 46: 1-46.

Barwise, Jon, and Robin Cooper. 1981. Generalized quantifiers and natural language. Linguistics and Philosophy 4: 159-219.

Bennis, Hans. 2004. Pronoms de la deuxième personne en néerlandais: Contrastes en forme et en interpretation. Franco-British Studies 33 (34): 10-22.

Berendsen, Egon. 1986. The phonology of cliticization. Dordrecht: Foris.

Bliss, Heather, and Bettina Gruber. 2015. Temporal restrictions on personal pronouns: The composition of Blackfoot proclitics. Lingua 156: 175-199.

Bolinger, Dwight. 1979. To catch a metaphor: You as norm. American Speech 54: 194-209.

Cardinaletti, Anna, and Michal Starke. 1999. The typology of structural deficiency: A case study of the three classes of pronouns. In Clitics in the languages of Europe, ed. Henk van Riemsdijk, 145-233. Berlin: Mouton de Gruyter.

Carlson, Gregory N. 1980. Reference to kinds in English. New York: Garland Publishing.

Carlson, Gregory N. 1989. The semantic composition of English generic sentences. In Properties, types, and meaning, ed. Gennaro Chierchia, Barbara H. Partee, and Raymond Turner, volume 2: Semantic Issues, 167-191. Dordrecht: Kluwer Academic Publishers.

Carlson, Gregory N., and Francis Jeffry Pelletier (eds.). 1995. The generic book. Chicago: The University of Chicago Press.

Chierchia, Gennaro. 1995. The variability of impersonal subjects. In Quantification in natural languages, ed. Emmon Bach, Eloise Jelinek, Angelika Kratzer, and Barbara H. Partee, 107-143. Dordrecht: Kluwer Academic Publishers.

Chomsky, Noam. 1995. The minimalist program. Cambridge, MA: MIT Press.

Cinque, Guglielmo. 1988. On si constructions and the theory of arb. Linguistic Inquiry 19: 521-582.

Cohen, Ariel, and Nomi Erteschik-Shir. 2002. Topic, focus, and the interpretation of bare plurals. Natural Language Semantics 10: 125-165.

de Hoop, Helen, and Sammie Tarenskeen. 2014. It's all about you in Dutch. Journal of Pragmatics 88: $163-175$.

Déchaine, Rose-Marie, and Martina Wiltschko. 2002. Decomposing pronouns. Linguistic Inquiry 33: 409_ 442.

Déchaine, Rose-Marie, and Martina Wiltschko. 2010. When and why can $1^{\text {st }}$ and $2^{\text {nd }}$ person pronouns be bound variables?. Manuscript, University of British Columbia. 
Demirdache, Hamida, and Myriam Uribe-Etxebarria. 1997. The syntax of temporal relations: A uniform approach to tense and aspect. In Proceedings of WCCFL 16, ed. Curtis Emily, Lyle James, and Gabriel Webster, 145-159. Stanford: CSLI Publications.

Demirdache, Hamida, and Myriam Uribe-Etxebarria. 2000. The primitives of temporal relations. In Step by step: Essays on minimalist syntax in honor of Howard Lasnik, ed. Roger Martin, David Michaels, and Juan Uriagereka, 157-186. Cambridge, MA: MIT Press.

Demirdache, Hamida, and Myriam Uribe-Etxebarria. 2007. The syntax of time arguments. Lingua 117: 330-366.

Egerland, Verner. 2003. Impersonal pronouns in Scandinavian and Romance. Working Papers in Scandinavian Syntax 71: 75-102.

Elbourne, Paul D. 2005. Situations and individuals. Cambridge, MA: MIT Press.

Enç, Mürvet. 1987. Anchoring conditions for tense. Linguistic Inquiry 18: 633-657.

Etxeberria Otaegi, Urtzi. 2005. Quantification and domain restriction in Basque. Doctoral Dissertation, University of the Basque Country.

Everaert, Martin. 1986. The syntax of reflexivization. Dordrecht: Foris.

Geist, Ljudmila. 2007. Predication and equation in copular sentences: Russian vs. English. In Existence: Semantics and syntax, ed. Ileana Comorovski, and Klaus von Heusinger, 79-105. Berlin: Springer.

Gillon, Carrie. 2006. The semantics of determiners: Domain restriction in Skwxwú7mesh. Doctoral Dissertation, University of British Columbia, Vancouver.

Gruber, Bettina. 2013. The spatiotemporal dimensions of person: A morphosyntactic account of indexical pronouns. Doctoral Dissertation, Utrecht University, Utrecht.

Heim, Irene. 1982. The semantics of definite and indefinite noun phrases. Doctoral Dissertation, University of Massachusetts, Amherst.

Heim, Irene, and Angelika Kratzer. 1998. Semantics in generative grammar. Oxford: Blackwell.

Holmberg, Anders. 1986. Word order and syntactic features in the Scandinavian languages and English. Doctoral Dissertation, University of Stockholm, Stockholm.

Jackendoff, Ray S. 2007. Language, consciousness, culture: Essays on mental structure. Cambridge, MA: MIT Press.

Kadmon, Nirit. 1992. On unique and non-unique reference and asymmetric quantification. New York: Garland Publishing.

Kayne, Richard. 1975. French syntax: The transformational cycle. Cambridge, MA: MIT Press.

Kitagawa, Chisato, and Adrienne Lehrer. 1990. Impersonal uses of personal pronouns. Journal of Pragmatics 14: 739-759.

Koster, Jan. 1978. Locality principles in syntax. Dordrecht: Foris.

Kratzer, Angelika. 1995. Stage-level and individual-level predicates. In The generic book, ed. Gregory N Carlson, and Francis Jeffry Pelletier, 125-175. Chicago: The University of Chicago Press.

Kratzer, Angelika. 1996. Severing the external argument from its verb. In Phrase structure and the lexicon, ed. Johan Rooryck, and Laurie Zaring, 109-137. Dordrecht: Kluwer Academic Publishers.

Kratzer, Angelika. 1998. More structural analogies between pronouns and tenses. In SALT VIII, ed. Devon Strolovich, and Aaron Lawson, 92-110. Amherst: GLSA.

Kratzer, Angelika. 2006. Making a pronoun. Fake indexicals as windows into the properties of pronouns. http://semanticsarchive.net/Archive/WI1OThiO/.

Krifka, Manfred, Francis Jeffry Pelletier, Gregory N. Carlson, Alice ter Meulen, Godehard Link, and Gennaro Chierchia. 1995. Genericity: An introduction. In The generic book, ed. Gregory N. Carlson, and Francis Jeffry Pelletier, 1-124. Chicago: The University of Chicago Press.

Maier, Emar, and Kees de Schepper. 2010. Fake Indexicals in Dutch: A challenge for Kratzer (2009). Manuscript: Radboud University Nijmegen.

Malamud, Sophia A. 2012. Impersonal indexicals: One, you, man and du. Journal of Comparative Germanic Linguistics 15: 1-48.

Martí, Luisa. 2003. Contextual variables. Doctoral Dissertation, University of Connecticut.

Moltmann, Friederike. 2006. Generic one, arbitrary PRO and the first person. Natural Language Semantics 14: 257-281.

Musan, Renate. 1995. On the temporal interpretation of noun phrases. Doctoral Dissertation, Massachusetts Institute of Technology.

Neeleman, Ad, and Kriszta Szendröi. 2007. Radical pro drop and the morphology of pronouns. Linguistic Inquiry 38: 671-714. 
Partee, Barbara H. 1987. Noun phrase interpretation and type-shifting principles. In Studies in Discourse Representation Theory and the theory of generalized quantifiers, ed. Jeroen Groenendijk, Dick de Jongh, and Martin Stokhof, 354-366. Dordrecht: Foris.

Partee, Barbara H. 1989. Binding implicit variables in quantified contexts. In CLS 25, Part One, The general session, ed. Caroline Wiltshire, Randolph Graczyk, and Bradley Music, 342-365. Chicago: University of Chicago, Chicago Linguistic Society.

Pesetsky, David, and Esther Torrego. 2007. The syntax of valuation and the interpretability of features. In Phrasal and clausal architecture: Syntactic derivation and interpretation, ed. Simin Karimi, Vida Samiian, and Wendy K. Wilkins, 262-294. Amsterdam: Benjamins.

Postal, Paul. 1966. On so-called pronouns in English. In Report of the 17th annual round table meeting on languages and linguistics, ed. Francis Dinneen, 177-206. Washington, D.C.: Georgetown University Press.

Preminger, Omar. 2011. Agreement as a fallible operation. Doctoral Dissertation, Massachusetts Institute of Technology.

Reinhart, Tanya. 1983. Anaphora and semantic interpretation. London: Croom Helm.

Reinhart, Tanya. 2002. The theta system: An overview. Theoretical Linguistics 28: 229-290.

Reuland, Eric. 2001. Primitives of binding. Linguistic Inquiry 32: 439-492.

Ritter, Elizabeth, and Martina Wiltschko. 2009. Varieties of INFL: TENSE, LOCATION, and PERSON. In Alternatives to cartography, ed. Hans Broekhuis, Jeroen van Craenenbroeck, and Henk van Riemsdijk, 153-202. Berlin: Mouton de Gruyter.

Ritter, Elizabeth, and Martina Wiltschko. 2014. The composition of INFL: An exploration of tense, tenseless languages, and tenseless constructions. Natural Language and Linguistic Theory 32: 1331-1386.

Rullmann, Hotze. 2004. First and second person pronouns as bound variables. Linguistic Inquiry 35: 159168.

Siewierska, Anna. 2004. Person. Cambridge: Cambridge University Press.

Speas, Margaret, and Carol L. Tenny. 2003. Configurational properties of point of view roles. In Asymmetry in grammar, ed. Anna Maria Di Sciullo, 314-344. Amsterdam: John Benjamins.

Stowell, Tim. 1993. The syntax of tense. Manuscript, UCLA, Los Angeles.

Stowell, Tim. 1995. The phrase structure of tense. In Phrase structure and the lexicon, ed. Laurie Zaring, and Johan Rooryck, 277-291. Dordrecht: Kluwer Academic Publishers.

Stowell, Tim. 2007. The syntactic expression of tense. Lingua 117: 437-463.

Tarenskeen, Sammie. 2010. From you to me (and back)—the flexible meaning of the second person pronoun in Dutch. Master's thesis, Radboud University Nijmegen.

van Koppen, Marjo. 2005. One probe-two goals: Aspects of agreement in Dutch dialects. Doctoral Dissertation, Leiden University.

van Koppen, Marjo. 2012. The distribution of phi-features in pronouns. Natural Language and Linguistic Theory 30: 135-177.

von Fintel, Kai. 1994. Restrictions on quantifier domains. Doctoral Dissertation, University of Massachusetts, Amherst.

Weerman, Fred, and Jacqueline Evers-Vermeul. 2002. Pronouns and case. Lingua 112: 301-338.

Westerståhl, Dag. 1984. Determiners and context sets. In Generalized quantifiers in natural languages, ed. Johan van Benthem, and Alice ter Meulen, 45-71. Dordrecht: Foris.

Williams, Edwin. 1983. Semantic vs. syntactic categories. Linguistics and Philosophy 6: 423-446.

Wiltschko, Martina, and Elizabeth Ritter. 2015. Animating the narrow syntax. The Linguistic Review 32: 869-908.

Wurmbrand, Susi. 2012a. Agree(ment): Looking up or looking down?. MIT Guest Lecture Handout.

Wurmbrand, Susi. 2012b. The syntax of valuation in auxiliary-participle constructions. In Coyote Papers, Vol. 20, ed. Jaehoon Choi, E. Alan Hogue, Jeffrey Punske, Deniz Tat, Jessamyn Schertz, and Alex Trueman, pp. 154-162. Tucson: University of Arizona.

Zagona, Karen. 1990. Times as temporal argument structure. Manuscript, Seattle: University of Washington.

Zeijlstra, Hedde. 2008. On the semantics and pragmatics of pronominal features. Handout CIL 18, Korea University, Seoul.

Zobel, Sarah. 2010. Non-standard uses of German 1st person singular pronouns. In New frontiers in artificial intelligence: JSAI-isAI 2009 Workshops, ed. Kumiyo Nakakoji, Yohei Murakami, and Eric McCready. Berlin: Springer.

Zwart, Jan-Wouter. 1996. Clitics, scrambling, and head movement in Dutch. In Approaching second. Second position clitics and related phenomena, ed. Aaron L. Halpern, and Arnold M. Zwicky, 579-611. Stanford: CSLI. 